\title{
Os açorianos no Rio de Janeiro - inserção social e estabelecimento
}

\section{Daniel Evangelho Gonçalves*}

\section{Emigração Açoriana}

A principal característica do povo açoriano, desde o povoamento das ilhas até os dias de hoje, é a emigração. Separados de todos os continentes por léguas e léguas de mar, os açorianos sempre sobreviveram mediante toda a adversidade. Espalharam-se pelo mundo e, no Brasil, ajudaram a colonizar o território, semeando a terra não só com alimentos, mas com cultura, religiosidade e tradiçôes.

Em todo momento que o povo açoriano se viu-se ameaçado por uma quebra de colheitas, estiagem, dificuldades comerciais, diminuiçáo dos fluxos de mercadorias estrangeiras, vulcóes, sismos ou pressôes políticas e religiosas; ele olhou para o mar e se lançou à emigração. Um de seus principais destinos era, e ainda é, a América, com destaque para os Estados Unidos da América (EUA) e o Brasil. Porém, embora deixasse sua terra natal, carregava consigo uma forte identidade regional que semeou e que continua a dar frutos em diversas culturas.

O açoriano está imerso em um processo histórico balizado por uma estrutura social favorável à emigração. Seja nos primórdios de um domínio senhorial que evoluiu para uma desigualdade de classes, oriunda do mau aproveitamento agrícola, e para um baixo investimento tecnológico exemplificado na falta de in-

* Doutorando em História pela Universidade Salgado de Oliveira (UNIVERSO); Mestre em Tecnologia pelo Centro Federal de Educação Tecnológica Celso Suckow da Fonseca - Rio de Janeiro (CEFET-RJ); Pós-graduado em História do Rio de Janeiro pela Universidade Federal Fluminense (UFF); graduado e licenciado em História pela Universidade Federal do Rio de Janeiro (UFRJ). 1o Tenente Historiador e Gestor de Patrimônio Cultural da Força Aérea Brasileira. Diretor Cultural da Casa dos Açores do Rio de Janeiro, responsável pelos eventos culturais e acadêmicos da Instituiçáo, e pesquisador da imigraçáo e associativismo açoriano para a cidade do Rio de Janeiro. E-mail: tenentedeg@gmail.com 
dústrias; seja pelas epidemias e guerras que o faziam vislumbrar outras realidades fora de seu lar. A concentração de terras nas mãos de poucas famílias sempre fez com que seu arrendamento aumentasse a desigualdade social, já que a maioria dos açorianos estava presa ao pagamento do uso das quintas. ${ }^{1}$

O estudo de Carlos Enes (1994) aponta que "no arquipélago, o período mais agudo da emigração correu na primeira década do século XX: os 57.853 indivíduos emigrados correspondem a uma saída média diária de 15,8 pessoas" (p. 38), número considerado elevado para uma pequena população. Segundo o mesmo historiador, entre 1901 e 1920, a emigração para os EUA correspondia a 80,9\% no distrito de Angra do Heroísmo. ${ }^{2}$ Entretanto, entre 1921 e 1930, a emigração portuguesa direcionada ao Brasil correspondia a $66 \%$, enquanto aos EUA a apenas $5 \%$.

A diminuição do fluxo para as terras Estadunidenses ocorreu devido ao entrave criado por leis americanas direcionando a população migrante para outros continentes a partir da década de 1950. Esse período apresenta, pela primeira vez, a emigração de açorianos de forma significativa para o Rio de Janeiro e São Paulo, advindos principalmente da Ilha Terceira e da Ilha de São Miguel. Ambas as Ilhas enfrentaram grande crise econômica com redução da demanda mundial de gêneros alimentícios produzidos no Arquipélago, causada, entre outros fatores, pela Primeira Grande Guerra. A Ilha Terceira, entretanto, sofreu maior impacto devido a não diversificaçáo da sua economia, diferentemente da Ilha de São Miguel, que procurou se adaptar ao mercado, embora também tenha contado com grande número de imigrantes assolados pela crise.

\section{Prováveis causas da escolha do Rio de Janeiro como destino}

A imigração portuguesa para o Brasil tende a se concentrar nos estados do Rio de Janeiro e São Paulo entre meados do século XX e seu final. Isto advém de um processo histórico que inicia, no século XVIII, com a longa crise da economia açucareira no Nordeste. Nada foi feito para diversificar a economia desta Região, que fora afetada ainda mais com o fim da escravidão. A produção de algodão, que vinha crescendo em meados do século XIX no Maranháo, decaiu rapidamente após a recuperação da agricultura Norte-Americana em consequência de sua Guerra Civil. Assim como o ciclo da borracha na Amazônia, que teve seu fim

1 Propriedade rurais de grandes dimensôes em Portugal e em outros países lusófonos, normalmente com casa de habitação.

2 Capital da Ilha Terceira, uma das nove ilhas do Arquipélago dos Açores, Região Autônoma de Portugal. 
rapidamente graças à concorrência asiática.

Enquanto São Paulo atraía imigrantes para substituir os escravos nas lavouras de café, produto que sustentava a economia do país, por meio de uma imigração subvencionada ou subsidiada pelo governo brasileiro; no Rio de Janeiro, a maioria dos imigrantes chegava por conta própria ou com o auxílio de familiares e amigos, atraídos pelo sucesso de seus conterrâneos no setor comercial.

O Rio de Janeiro era a capital da República, cidade em franca expansão econômica, maior centro comercial e bancário do país e pioneiro na industrialização. Por isso, atraía milhares de imigrantes de todas as partes do mundo, principalmente portugueses, graças à proximidade cultural e linguística, além das redes comerciais e sociais estabelecidas desde os tempos colônias.

Havia cerca de 30 milhões de habitantes no Brasil em 1920. Dentre eles, 1.565.961 eram imigrantes, dos quais 433.567 eram portugueses. Sua maioria concentrava-se no Distrito Federal (Rio de Janeiro), totalizando 172.338 habitantes, era a maior colônia, representando $14 \%$ do total de estrangeiros na cidade (Lobo, 2001, p. 44). De acordo com a autora (2001, p. 34), os portugueses eram proprietários ou ocupavam grande parte dos postos de trabalho dos setores comerciais e industriais de atacado e varejo; eram também donos de imóveis (recebendo grandes quantias oriundas dos aluguéis) e estavam presentes nos setores bancários, além de representarem um destacado mercado consumidor de artigos de exportação lusos. Antônio Torres (1925), jornalista antilusitano, afirmava que os portugueses eram proprietários de $85 \%$ das empresas comerciais do Distrito Federal em 1923. Eles davam preferência para a importação de artigos portugueses e empregavam exclusivamente seus conterrâneos, remetendo seus lucros à Portugal, o que prejudicava a economia brasileira. Dentre esses estavam também os açorianos.

Nas décadas de 1920 e 1930, os açorianos estabelecidos com sucesso davam preferência à contratação de seus conterrâneos, criando uma rede de apoio local. Esses imigrantes chegavam por meio das Cartas de Chamada. Nessa época, o governo Vargas procurou bloquear a vinda de estrangeiros por meio da Lei de Cotas de Imigração, que reforçava sua política nacionalista, com exceção dos de nacionalidade portuguesa, dado o acordo bilateral firmado com o presidente de Portugal António de Oliveira Salazar. As Cartas de Chamada eram dirigidas aos parentes, amigos ou conhecidos bem referenciados, mas sem suporte econômico. O emissor da carta convidava o emigrante e ficava responsável por ele (inclusive legalmente), estreitando os laços de solidariedade. Essa prática marcou a vinda de quase todos os emigrantes açorianos nessa e em outras épocas futuras.

Quanto à legislação sobre as Cartas de Chamada, ressalta-se que, em 1911, foi lançado um ordenamento regulamentando a imigração no Brasil. O decreto $n^{\circ} 9.081$ estabeleceu normas para a entrada dos estrangeiros no país. Mais tarde, em 1945, entrou em vigor uma nova legislação que aprimorava as normas 
para a entrada de imigrantes no país, a fim de reordenar os diversos grupos que não paravam de chegar devido ao pós-guerra. Essa legislação procurava proteger os interesses do trabalhador nacional e desenvolver a imigração, com o intuito de torná-la um fator de progresso para o país, conforme está descrito no Decreto Lei n. 7967 de 18 de setembro de 1945 (Croci, 2008).

Os açorianos chamavam os amigos e parentes por confiarem apenas neles, isto, por sua vez, contribuía para uni-los ainda mais, estreitando os laços de reciprocidade e mantendo a comunidade fechada. $\mathrm{O}$ contato desses amigos e parentes favorecia os casamentos dentro da própria comunidade e novas relaçóes comerciais de sociedade. Conforme salientado por Judite Evangelho: "a acolhida solidária aos recém-chegados perpetuava-se com atitudes de confiança recíproca patrão-empregado. A profissáo se diferenciava por uma mão de obra sem exigências especializadas, mas ligada a laços familiares e sociais de origem." (2012, p. 92).

Nos anos entre 1920 e 1940, foi registrada a saída de 5.025 açorianos, sendo $44.5 \%$ (2.234 pessoas) com destino ao Rio de Janeiro e 36.8\% (1.851 pessoas) com destino à São Paulo, sem considerar os açorianos com destino ao Brasil, sem estado definido, que somavam 16.5\% (833 pessoas). As ilhas São Miguel e Terceira, se somadas, aumentam o percentual das emigraçóes para $90,65 \%$, sendo 2.930 açorianos (58,31\%) oriundos de São Miguel e 1.625 (32,34\%), da Terceira. Essas ilhas apresentavam o maior contingente populacional e sofriam mais com as crises econômicas do arquipélago.

Três quartos desse contingente emigratório foram registrados na década de 1920. Entre 1931 e 1940, a taxa de emigração declinou, chegando ao mínimo, no ano de 1931 , de apenas 30 emigrantes $(0,60 \%)$, provavelmente devido à crise causada pela Revolução de 1930 e às mudanças governamentais que traziam incertezas ao emigrante. Para o Rio de Janeiro, a Ilha Terceira registrou o maior número de emigrados e para São Paulo, aqueles nascidos em São Miguel. Quanto à profissão, os registros apontam que 48,05\% dos emigrantes eram agricultores, o que explica a ocupação laboral dessa população ao chegar no Brasil (Evangelho, 2012).

A década de 1950 ressurge com grande vocação migratória por causa do Salazarismo. Um estudo do fenômeno migratório (Rocha, 2009) ressalta que, entre 1966 e 1975, no fim do Governo de Salazar, as migraçóes chegaram a seu ápice. Registraram-se cerca de 10.800 imigrantes açorianos por ano, em um total de 108.000 pessoas. Mesmo que o Brasil não tenha sido o destino mais procurado, já que as leis que barravam os emigrantes nos EUA foram modificadas. Segundo Elis Angelo:

Durante o período do Estado Novo, que se iniciou em 1933 - e por isso é relevante para a compreensão de parte das saídas das ilhas açorianas - surgiram algumas questóes que se tornaram definitivas para a tomada 
de decisáo dos sujeitos que almejavam melhores condiçóes de vida. Nos depoimentos e nas pesquisas efetuadas os elementos que aparecem com mais frequência como aquelas que concorrem para a emigração no decorrer dos anos 1950, são a ausência de emprego, fundamentando a questão econômica, e a fuga de possíveis alistamentos para atuar na África, onde as colônias estavam constantemente em conflito com Portugal. No entanto, eram principalmente os problemas financeiros que impossibilitavam a permanência no país. (2015, p. 35-36).

Elis Angelo explica também o quanto a fuga das guerras coloniais, no final do Governo de Salazar, foi determinante para o aumento da emigração, e que a escolha pelo Brasil, especificamente para Rio de Janeiro e São Paulo, estava ligada às redes de reciprocidade já lá estabelecidas:

Praticamente todos os entrevistados emigraram para fugir da "guerra" alguns para salvar seus filhos, outros para se esquivarem da obrigatoriedade de servir ao exército. Buscavam junto a amigos e parentes trabalho, casa e melhores oportunidades. [...] O Brasil era a melhor saída, haja vista que muitos açorianos já se encontravam no país e mandavam notícias de possibilidades de emprego e de um cotidiano sem tantas adversidades, como pobreza, falta de infraestrutura, calamidades, terremotos, entre outras. (2015, p. 89-90).

Após o fim do Governo de Salazar, os registros da imigração açoriana para as cidades do Rio de Janeiro e São Paulo diminuíram drasticamente. Esse fenômeno pode ser explicado pelas melhores condiçôes de vida no próprio arquipélago, geradas pelas inovaçóes tecnológicas que preveniam as catástrofes naturais e pela autonomia política e administrativa diante do Governo Central de Portugal. Assim como, por outros locais, como a América do Norte, voltarem a ser mais atrativos que o Brasil.

\section{Inserção social e econômica dos açorianos no Rio de Janeiro}

A emigração atingiu todas as ilhas dos Açores, e é rara alguma família no arquipélago que não tenha um parente emigrado. Entre as décadas de $1920 \mathrm{e}$ 1970, dos açorianos emigrados para o Rio de Janeiro, a maioria foi de terceirenses. Para a maior parte deles, a cidade do Rio de Janeiro representou estabilidade financeira e prosperidade, oriunda do trabalho manual, a ponto de se formar uma nova 
classe média nos Açores. Isto se deu por meio das remessas de dólares enviadas às famílias ou pelos próprios açorianos que regressaram, gerando uma economia solidária para com os parentes desfavorecidos e incentivando a emigração de outros que os viam como exemplo.

O Rio de Janeiro estava em constante expansão e atraiu os emigrantes portugueses por ser o principal porto (entrada e saída de produtos e capitais devido a recuperação do café), onde estavam as primeiras fábricas (principalmente tecidos) que geravam emprego na indústria, além da demanda de mão de obra, na construçáo civil, gerada pelo crescimento da cidade. Nesse início da República, os portugueses passam a dominar setores da economia, tais como: transporte (carroças), setores de serviços financeiros, pequenas indústrias, abastecimento das cidades (hortas e vacarias) e, acima de tudo, comércio.

Wagner Chagas Mendes (1998) fez um levantamento do pequeno comércio varejista da época (açougues, padarias, secos e molhados, peixarias, restaurantes, casas de pasto, botequins, armarinhos e fazendas) e constatou que $60,6 \%$ pertencia aos portugueses. Estes chegavam a dominar quase $50 \%$ dos estabelecimentos comerciais no centro do Rio de Janeiro. Portugueses e seus descendentes eram mais da metade da população carioca. Os açorianos estavam inseridos nesse contexto, com predominância nas Vacarias, na Zona Norte e Central da cidade, do início da década de 1900 até 1937, ano de sua decadência.

Entre as décadas de 1900 e 1930, na cidade do Rio de Janeiro, a atuação profissional desses ilhéus, de maioria terceirense, estava ligada assim à produção de leite em estábulos, distribuídos por toda a cidade, principalmente nas regióes central e Zona Norte. O que demonstra a continuidade das ocupaçóes laborais exercidas nos Açores, já que a Ilha Terceira era a maior produtora de leite do arquipélago. Na maioria dos casos, os ilhéus chegavam sem capital para investir e passavam anos trabalhando para outros açorianos abastados, economizando tudo que podiam até abrir seu próprio negócio.

A importância dessa inserção econômica era notória. Eram os açorianos que abasteciam os lares cariocas de leite, distribuídos de porta em porta. Sua ocupação acabou contribuindo para as características geográficas que diversos bairros cariocas adquiriram. Os ilhéus, inicialmente, moravam "de favor" nos lares de amigos e parentes, até adquirirem condiçóes de ter sua própria moradia. Os laços de reciprocidade e solidariedade estabelecidos faziam com que escolhessem locais próximos de seus conterrâneos, tanto para residir quanto para exercer sua ocupação comercial. Acabavam por deixar marcas culturais nos locais escolhidos. Portanto, a paisagem dos bairros do Rio de Janeiro também era definida pela ocupação dos açorianos.

Judite Evangelho (2012) fez um levantamento sobre essa ocupação comercial. Segundo a autora, havia 352 estábulos na Cidade do Rio de Janeiro em 
1903. Em 1907, o número de vacas chegava a 3.045. Os estábulos apresentavam mão de obra familiar, mas, em sua maioria, contavam também com quatro a cinco funcionários contratados (geralmente conterrâneos e, em alguns casos, brasileiros). Cada estábulo detinha cerca de cinco a sete vacas no início da década de 1920; com o sucesso do empreendimento, chegaram a possuir de 20 a 40 vacas. Preparava-se a alimentação (basicamente capim) e forragem para o gado. Ordenhava-se bem cedo. Depois, limpava-se o estábulo, enchia-se os tonéis e partia para a distribuição do leite nas redondezas. $\mathrm{O}$ transporte era feito em carroças, bicicletas ou a pé, assim como era feito nos Açores. Em alguns casos, levava-se a própria vaca com seu filhote ao lado, para retirar o leita na hora. Muitos estábulos mantinham, em anexo, açougues ou armarinhos. Geograficamente, ocupavam o espaço dos bairros da Tijuca, Maracaná, Santa Tereza, Catete e Estácio.

Para o infortúnio dos açorianos, a relativa prosperidade durou pouco. Durante o governo Vargas, a paisagem e as estruturas da cidade mudaram, seguindo as novas diretrizes políticas sanitárias e urbanísticas. A preocupação com a saúde pública culminava em pesadas multas a quem descumprisse as novas normas. $\mathrm{O}$ fim das vacarias estava próximo. Desde 1904, quando foram decretadas a remoção dos excrementos de gado em vias públicas e a extinção dos capinzais em áreas urbanas, a produçáo de leite e a circulação das vacas já se tornaram dificultosas, porém a fiscalização não era tão rigorosa quanto viria a se tornar. Nos finais da década de 1930, a modernização trazida pelos projetos urbanísticos e sanitários, do governo Vargas, que abriram novas ruas e avenidas, contribuiu para o fechamento dos antigos estábulos que estavam, literalmente, no caminho das reformas. Passar com as vacas por essas novas ruas já não era possível.

A concorrência também se tornou desleal. Crescia a produção industrial leiteira em Minas Gerais, que distribuía seu leite por meio de ferrovias com vagóes refrigerados e investia em tecnologia de conservaçáo e distribuição da mercadoria. Todas as etapas da produção e distribuição desse leite seguiam as normas do Governo, enquanto os açorianos lutavam, com a ajuda de seus sindicatos, para adequar sua produção aos novos tempos. Outro fator importante foi o aumento da vigilância promovida pela saúde pública. Muitos açorianos tiveram suas vacas confiscadas com suspeita de estarem com tuberculose, pois era comum acreditar que essa doença poderia ser transmitida aos seres humanos através do leite. Após apreendidas pelos agentes de saúde, muitas vacas não retornavam aos seus donos. Não havia a confirmação se estavam doentes ou não, e o governo não pagava nenhuma indenização pelas vacas confiscadas, mesmo que os açorianos batalhassem por isso, intermediados pelo sindicato responsável. Havia também a suspeita dos açorianos misturarem água ao leite para aumentar seus lucros, contribuindo para o clima de desconfiança que diminuía a clientela.

Todas essas medidas foram diminuindo o capital financeiro dos açorianos 
no Rio de Janeiro, ao mesmo tempo que os novos decretos forçavam os ilhéus que pretendiam continuar no ramo das vacarias a se afastarem dos centros urbanos e migrarem para outras regiôes, como Campo Grande, Realengo e Jacarepaguá. Todavia, com a "derrota" dos estábulos, a maioria dos açorianos migrou para o comércio, botequins, restaurantes, frigoríficos e com destaque para os açougues ("talhos"); também para a agricultura, entre outros. Não existe uma comprovação, mas tudo indica que a mudança para o comércio de carnes foi natural: já havia açougues nos anexos das propriedades, sendo uma prática conjunta, assim como uma rede de contatos entre aqueles que trabalhavam com os talhos. Foi uma alternativa para não deixar a cidade.

Com o passar dos anos, o açoriano começou a dominar o mercado de açougues e as redes de reciprocidade ou de apoio fizeram com que emigrantes perpetuassem essa prática. Isto porque o açoriano geralmente tinha pouco estudo e qualificação e acabava por ocupar cargos cuja força motriz era seu próprio esforço físico.

A história oral contribui para o enriquecimento das narrativas históricas e mesmo para a construção de teorias e conceitos. Neste artigo, selecionamos duas entrevistas com açorianos, que emigraram em momentos distintos, oriundos da Ilha Terceira, convergindo para as hipóteses levantadas. A primeira entrevista foi realizada no dia 19 de outubro de 2018, com o Sr. João Vaz Teixeira, 87 anos, natural da freguesia da Ribeirinha, cidade de Angra do Heroísmo, e emigrado na década de 1950, quando os açougues começavam a assumir o lugar preponderante no sustento da comunidade açoriana. A segunda foi realizada, no dia 10 de novembro de 2018, com o Sr. Manuel Gonçalves Borba, 74 anos, natural da freguesia de Santo Amaro, cidade de Angra do Heroísmo. Ele chegou ao Rio de Janeiro na década de 1960, época próspera que consolidou a primazia açoriana nesse tipo de comércio.

A seguir, destacamos aspectos relevantes da entrevista do Sr. João Vaz:

Eu vim sozinho em 1956. Pensava: "vou ficar 5 ou 6 anos no Brasil, arrumar um dinheiro e voltar pra resolver minha vida. Escolhi o Brasil porque para a América eles não aceitavam. Não foi tanto por causa de amigos ou família, e sim porque queria "arrumar minha vida". Então escrevi uma carta para meu primo Antônio, filho de irmãos do meu pai. Mas, quem ficou responsável por mim foi o pai dele, o meu tio Francisco Anicete. Cheguei e já fui logo trabalhar no açougue dele na rua Grão Pará, no Lins de Vasconcelos. A gente vinha da ilha pra trabalhar, quem chamava a gente tinha açougue então era pra lá que a gente ia. Até tinha outras coisas, se a gente procurasse, mas já queríamos "ganhar a vida", entâo, já começávamos no açougue. A casa trabalhava bem. Mas eles não percebiam os 
erros. Teve uma vez que eles limparam a carne e cobraram 28 cruzeiros e 50, eu cobrei 29 e ele achou ruim. Eu falei que, se ele pesasse antes, ia ter 100 gramas a mais. Ele teimou comigo e eu falei pra ele arrumar outro funcionário porque eu ia "arrumar a minha vida" e fui embora. Eu não queria passar por ladrão sem ser. Ai ele disse: "Tu aqui não vais ganhar dinheiro nunca!". Eu fiz apenas o primário quando estava servindo a tropa no Exército, com 21 anos e nunca tinha sido comerciante antes de vir para o Brasil. Não gosto muito de ler, mas contas era comigo. Em menos de dois anos eu já comprei a sociedade de um açougue. Cheguei a ter sociedade em 11 ou 12 açougues ao mesmo tempo. Está bom para quem não ia ganhar dinheiro né?! Quando fui casar lá na Ilha Terceira, levei 18 mil dólares dentro de um baú, naquele tempo isso era muito dinheiro, para casar e ajudar a família e ainda trouxe dinheiro de volta. Quando vim para o Brasil queria ficar pouco tempo, mas aqui era tão bom, tão bom que casei, trouxe minha mulher e quis fazer minha vida aqui. (João Vaz Teixeira, 2018).

Vale ressaltar que a fala do Sr. João Vaz corrobora os motivos da escolha pelo Rio de Janeiro. Para ele, a saída da ilha era necessária para alcançar uma melhor qualidade de vida. De início, os açorianos almejavam enriquecer e retornar, mas o sucesso no Brasil os fez querer ficar. As leis anti-imigração Norte Americanas e as guerras coloniais na África contribuíram para o deslocamento dos emigrantes para o Brasil. Ressaltamos também a trajetória das remessas de dinheiro dos emigrantes que ajudavam a sustentar o arquipélago.

Abaixo, constam outros pontos importantes destacados na fala do Sr. Manuel Borba:

Na Ilha Terceira, eu trabalhava na lavoura, estudava de noite, aí quando foi no tempo da guerra do Salazar resolvi vir para o Brasil. Não era para eu ir para o Brasil, eu via meus amigos embarcando e dizia que eu nunca sairia da ilha. Mas acabei indo por conta da guerra. Meus pais não queriam assinar porque eu era de menor. Aí eu perguntei a minha mãe: "A senhora quer que eu vá para guerra ou para o Brasil? Ela respondeu que preferia qualquer coisa menos a guerra e correu com tudo para que eu viesse para o Brasil. Em 1961, meu irmáo José fez a minha carta de chamada. Eu tinha 16 anos, e o processo não demorou nada, dei sorte, em três dias chegou a carta, aí eu cheguei dia 07 de novembro de 1961 . Trabalhei com meu irmão, de empregado, por quase 7 anos. Depois comecei a namorar minha esposa Lourdes. O irmão dela, o tio Luís, estava querendo parar de trabalhar e resolveu me chamar para vir para o açougue 
dele. Aí eu respondi: pô! Como é que vou comprar sua parte no açougue se eu não tenho dinheiro? Aí ele respondeu: "não se preocupe, não é minha única fonte de renda (ele tinha uns imóveis já que rendiam uns aluguéis), você vira meu sócio, vai me pagando por mês um pouquinho, sem juros até que pague tudo e acertamos o negócio”. Aí eu fiquei com a metade do açougue e estive lá quase 49 anos, na mesma casa sempre, na Haddock Lobo, na Tijuca, e também comecei a investir em imóveis com o dinheirinho que ia juntando, no Brasil e também nos Açores, na minha terra! E não uma casa qualquer, comprei a casa que era dos meus pais! Reformei e aumentei! E esta foi a minha vida, toda vez que sobrava um pouquinho eu comprava um imóvel, e foi assim devagarinho até eu chegar lá. Dava até pra ficar uns meses na Ilha sem me preocupar muito, deixa o meu sócio e os empregados tomando conta enquanto eu ia com a família de férias. Voltei 14 vezes a ilha, sempre que podia eu ia. Quando cheguei aqui, fui trabalhar em açougue. Encontrava os açorianos, mas poucas vezes, na década de 1960 a gente trabalhava sem parar, e estava cada um em um canto da cidade, Leblon, Tijuca, Zona Sul, Zona Norte, Centro. A gente se encontrava pouco, só Domingo de tarde, na nossa única folga na semana, porque trabalhávamos todo dia, até no domingo de manhã. (Manuel Gonçalves Borba, 2018).

Nessas entrevistas, podemos constatar que o motivo da saída dos Açores não é tanto o desejo de prosperidade econômica, mas sim a fuga das guerras do Governo de Salazar. Podemos observar também que os açougues eram uma escolha natural; seguiam o caminho dos emigrantes anteriores. Mesmo com a baixa escolaridade, o almejado enriquecimento era não só esperado, como possível e, via de regra, consequente, caso houvesse o empenho necessário. O comércio era próspero a ponto de poderem investir o excedente dos lucros e retornar à sua terra para passear.

Fica notória também a importância das redes de apoio local, fortalecidas pelas Cartas de Chamada, as quais possibilitavam moradia e sustento ao emigrante, geralmente encaminhado diretamente aos açougues, como garantia de emprego com grandes possibilidades de prosperar, conforme afirma Judite Evangelho:

Eles formavam um clã profissional que recrutava quase sempre funcionários dos Açores, a grande maioria terceirenses, principalmente para cargos de maior responsabilidade e confiança, como gerentes, sócios, caixas. Em várias ocasiôes os imigrantes evoluíram rapidamente de simples empregados a sócios-proprietários ou então funcionários com percentagens nos lucros líquidos. (2012 p. 12). 
O Brasil enfrentou, no final da década de 1980 e no início da década de 1990, um cenário de crise econômica e inflação descontrolada. Em seguida, a reforma econômica ocasionada pela implementaçáo do Plano Real, em 1994, responsável pela interrupção dessa inflação galopante da moeda Cruzeiro, estabilizou a economia e desvalorizou o dólar - muitos açorianos trocavam suas economias por dólares para viajar ou como investimento. Em consequência de tais acontecimentos, todo o comércio brasileiro ressentiu-se drasticamente, com os açougues também sendo diretamente atingidos. O declínio dessa atividade econômica acompanhou as décadas de crise brasileira. Além dos fatos relatados, nessa mesma época, acirrou-se a forte concorrência dos hipermercados, autorizados a vender carne por um preço consideravelmente menor. Esses fatores fizeram com que o nicho comercial açoriano no Rio de Janeiro entrasse em franco declínio até atingir a falência.

Novos estudos estáo sendo realizados para comprovar o surgimento, a evolução e a desvalorização desse setor produtivo majoritariamente açoriano. Em teoria, a ocupação comercial dos talhos ou açougues por parte dos ilhéus começou logo após a falência das vacarias, no fim da década de 1930. Ela teria evoluído nas décadas de 1940 e 1950, perdurando e prosperando entre as décadas de 1960 e 1970, tendo seu declínio entre o fim da década de 1980 e a primeira década dos anos 2000, quando praticamente deixou de existir.

Esse comércio tradicional, que unia os açorianos, entrou em decadência. As novas geraçóes foram incentivadas pelos seus pais a terem formação de nível superior e a se tornarem professores, funcionários públicos, ou seja, atores sociais em diversificados setores produtivos. Até atingirem o patamar atual de sincretismo cultural e econômico com a população carioca, abrindo a comunidade e não mais ocupando um lugar comercial específico.

\section{Considerações finais}

Os açorianos que vieram para o Rio de Janeiro migraram devido às dificuldades econômicas, calamidades geoclimáticas e guerras coloniais durante o governo de Salazar. Escolheram seu destino orientados pela proximidade linguística, acordos bilaterais entre os países envolvidos e redes de apoio local que os acolheram, oferecendo abrigo, trabalho e amparo de amigos e familiares.

Os locais receptores dos imigrantes têm características próprias que vão moldar o constructo dessas comunidades. De maneira geral, o açoriano que vem para o Rio de Janeiro é oriundo da Ilha Terceira, produtora de gado e laticínios. 
Mantém, portanto, no local de destino, as atividades produtivas de sua ilha, focando na produção e comercialização do leite e permanecendo assim ligado ao meio rural. Retira, da produção leiteira inserida no coração da cidade, o seu sustento, tornando-se responsável por abastecer os lares cariocas com esse produto.

Não obstante, o impacto das políticas públicas sanitárias do governo Vargas forçou os açorianos do Rio de Janeiro a saírem dos estábulos e migrarem para os açougues, dominando esse mercado. Por meio do contato social que setor comercial proporciona, espalhou hábitos, costumes e tradiçóes que se perpetuam até os dias atuais. Esse comércio também teve sua falência decretada, na década de 1990, devido à forte concorrência dos hipermercados e às crises e modificaçóes econômicas dos governos brasileiros.

Essas mudanças moldaram a comunidade açoriana a ponto de ocorrer sincretismo cultural com os cariocas, visto que ela agora precisava se relacionar economicamente e socialmente, adaptando-se muito mais à burocracia estatal e às crises financeiras para sobreviver e prosperar. Seus descendentes não mantiveram as características de isolamento de seus antepassados, misturando-se à sociedade local. A comunidade açoriana era extremamente fechada. Por essa razão a manutenção de vínculos sociais ou comerciais restringia-se ao âmbito interno. Poucos registros da presença açoriana são encontrados.

Entretanto, em futuras pesquisas, aproveitar-nos-emos desses laços de solidariedade com seus pares para buscar fontes que corroborem a continuidade dos estudos sobre esses imigrantes. por exemplo, funcionários de escritórios de contabilidade gerenciados e ligados à comunidade açoriana no Rio de Janeiro. A busca de dados estatísticos sobre a presença açoriana nas vacarias e no varejo de carnes, ao longo do século XX, também será feita no Arquivo Geral da Cidade do Rio de Janeiro, na Junta Comercial do Rio de Janeiro e nas Delegacias Fiscais da Prefeitura do Rio de Janeiro, que contém dados de registros de casas comerciais. Além da consulta dos bancos de dados de sócios da Casa dos Açores do Rio de Janeiro e da lista de doadores das Irmandades Particulares do Divino Espírito Santo, espalhadas pela cidade, que podem confirmar a existência, a abonança e o desaparecimento desse tipo de comércio.

Ressalta-se ainda que, desde a década de 1980, a economia dos Açores vem crescendo e oferecendo condiçóes para que seus habitantes parem de emigrar. Dentre essas condiçôes, destacam-se: as reformas ocasionadas pela reconstrução de parte da Ilha Terceira, após o grande terremoto de 1980; a entrada de Portugal na Uniâo Europeia e a consequente injeção de capital financeiro; as inovaçóes tecnológicas e, principalmente, o fato do arquipélago ter se tornado autônomo em 1977, garantindo controle sobre suas leis, impostos e políticas públicas e oferecendo, portanto, uma melhor condição de vida e emprego aos açorianos.

Estes são fatores explicativos para o enfraquecimento das comunidades 
açorianas no mundo, pois não há mais imigrantes da comunidade em grande escala, e os que emigraram já estão envelhecendo e morrendo. Hoje acontece um contra fluxo, os descendentes de açorianos buscam o arquipélago dadas as melhores condições de vida nele oferecidas

Admitindo o legado deixado pela comunidade açoriana, as marcas na memória de seus descendentes, na vida econômica e social da cidade que os acolheu, é necessário produzir e registrar a trajetória desses emigrantes, por meio de sua ocupaçáo comercial, em solo carioca. Esperamos, assim, em estudos futuros, contar um pouco mais da evolução histórica da cidade do Rio de Janeiro através do olhar, das marcas e das contribuiçóes deixadas pelos imigrantes açorianos.

\section{Referências}

ANGELO, Elis Regina Barbosa. Trajetórias dos Imigrantes Açorianos em São Paulo: Processos de Formação, Transformação e as Ressignificaçóes Culturais. Jundiaí: Paco Editorial, 2015.

CARLEIAL, Adelita. Redes sociais entre imigrantes. Anais Encontro Nacional de Estudos Populacionais. Caxambu: ABEP, 2004.

CROCI, Frederico. O chamado das cartas: migraçóes, cultura e identidade nas cartas de chamada dos italianos no Brasil. Locus: Revista do Departamento de História e do Programa de Pós-Graduação em História da Universidade Federal de Juiz de Fora, Juiz de Fora, v. 14, n. 2, 2008.

ENES, Carlos. A Economia Açoriana Entre as Duas Grandes Guerras Mundiais. Lisboa: Salamandra, 1994.

EVANGELHO, Judite Toste. Os Açorianos no Rio de Janeiro, 1860 - 2000. Rio de Janeiro: Letra Capital, 2012.

MENEZES, Wagner Chagas de. Costurando os retalhos: configuração e cotidiano do pequeno comércio de espaço central da cidade do Rio de Janeiro. Tese (doutorado) Instituto de Ciências Humanas, Universidade Federal Fluminense, 1998.

PACHECO, Alisalda. Terra Lavrada de Trigo. Ponta Delgada: Nova Gráfica - Lda, 2016.

PIRES, António M.B. Machado. Congresso dos Emigrantes Açorianos. Angra do 
heroísmo: [s/e], 1978.

PRADO, Maria Ligia Coelho. Repensando a História Comparada da América Latina. Revista de História, n. 153, p. 11-33, 2005.

ROCHA, Gilberta Pavão Nunes. A emigração nos Açores nos séculos XIX e XX - a necessidade, a solução, a valorização. Disponível em: <A\%20EMIGRAÇÃO\%20 AÇORIANA\%20PARA\%20O\%20BRASIL\%20RITMOS\%20E\%20DESTINOS.pdf $>$. Acesso em: 12 jun. 2018.

RUANO-BORBALAN, Jean-Claude. La construction de L'identité. In: HALPERN, Catherine; RUANO-BORBALAN, Jean-Claude (Org.). Identité(s): Lindividu, Le groupe, La société. Éditions Sciences Humaines: [S.I.], 2004.

SERPA, Caetano Valadão. A Gente dos Açores, Identificação - Emigração e Religiosidade - Séculos XVI - XX. Lisboa: Prelo Editora; S. A. R. L., 1978.

TORRES, Antônio. As razoes da inconfidência, obra histórica enriquecida de muytas e variadas notas. Rio de Janeiro: A. J. Castilho, 1925. p.71-72, 3. ed.

\section{Fontes orais}

TEIXEIRA, João Vaz [87 anos]. [out. 2018]. Entrevistador: Daniel Evangelho Gonçalves. Rio de Janeiro, RJ, 19 out. 2018.

BORBA, Manuel Gonçalves [74 anos]. [nov. 2018]. Entrevistador: Daniel Evangelho Gonçalves. Rio de Janeiro, RJ, 10 nov. 2018.

Resumo: $\mathrm{O}$ presente artigo procura levantar questôes a respeito da inserçáo social dos açorianos na cidade do Rio de Janeiro por meio de atividades laborais, marcada pela transição das atividades rurais para comerciais. Procura-se discutir a hipótese de que as escolhas por essas ocupaçóes são direcionadas pelas redes de apoio local e geradas pela procura de continuidade das atividades produtivas exercidas no arquipélago. A trajetória e o estabelecimento dos ilhéus açorianos na cidade do Rio de Janeiro ainda são pouco estudados. Apresentam características particulares dentro do universo de portugueses em solo carioca devido a sua peculiar situação social, econômica e geográfica. A emigração açoriana remete aos tempos coloniais, entretanto, teve aumento substancial para a cidade do Rio 
de Janeiro durante o século XX. Do início desse século até a década de 1940, a atividade econômica preponderante era a criação de gado leiteiro em pequenos estábulos em meio à cidade. Já, entre as décadas de 1950 até 1990, o nicho comercial dominante eram o de açougues.

Palavras-chave: Imigração portuguesa. Emigração açoriana. Ocupação comercial. Inserção. Estabelecimento.

\title{
Azorean islets in Rio de Janeiro - social integration and establishment
}

\begin{abstract}
This paper aims to raise questions concerning Azorean islets social integration into Rio de Janeiro city through work activities, which was characterized by the transition from rural to commercial activities. It is intended to discuss the hypothesis of these occupation choices are guided by the local support networks and originated from the demand of continuity of the productive activities executed in the Azores. The Azorean islets' trajectory and establishment in Rio de Janeiro city are still poorly studied. They present special characteristics within the Portuguese people universe in this land due to their peculiar social, economic and geographical situation. Azorean emigration dates to colonial times, however, it had a substantial increase to Rio de Janeiro city during the twentieth century. From the beginning of this century until the 1940s, the predominant economic activity was the breeding of dairy cattle in small stables in the middle of the city. Between the 1950s and the 1990s decades, nonetheless, the dominant commercial niche was the one of butchers.
\end{abstract}

Keywords: Portuguese immigration. Azorean emigration. Commercial occupation. Integration. Establishment.

Recebido em 20/08/2019

Aprovado em 03/10/2019 